\title{
HUBUNGAN PENGETAHUAN DAN SIKAP DENGAN UPAYA PENCEGAHAN ANEMIA GIZI BESI PADA SISWI DI SMAN 11 KOTA BENGKULU
}

\author{
Neti Sufenti $^{1}$, Nurul Khairani ${ }^{2}$, Sanisahhuri ${ }^{3}$ \\ 1,2,3Program Studi S1 Kesehatan Masyarakat STIKES Tri Mandiri Sakti Bengkulu \\ nsoeffenti@yahoo.com,nurul.sulaksono@gmail.com ${ }^{2}$
}

\begin{abstract}
The impacts of iron deficiency anemia are impaired intellectual and cognitive performance, causing delayed psychomotor development and decreased resistance to infectious diseases. The research type was Analytical Survey and Cross Sectional Design. The population in this study was all school girls of class XI and XII SMAN 11 Bengkulu City totaling 140 school girls. The research sample was taken by using the Accidental Sampling technique as many as 83 school girls. The data used are primary and secondary data using a questionnaire in the form of google form processed univariate and bivariate with the Chi-Square $\left(\chi^{2}\right)$ statistical test. The results showed that out of 83 school girls, 41 school girls (49.4\%) had good knowledge, 44 school girls (53.0\%) were favorable, and 45 school girls $(54.2 \%)$ made efforts to prevent anemia of good iron nutrition. Statistically, there was no relationship between knowledge and efforts to prevent iron deficiency anemia and there was no relationship between attitudes and efforts to prevent iron nutritional anemia. It is recommended that school routinely carry out educational activities in order to broaden knowledge in the field of health, especially about iron nutrition anemia for school girls so that they can play more active roles in preventing iron deficiency anemia.
\end{abstract}

Kata kunci: attitude, iron deficiency anemia, knowledge, prevention

\section{ABSTRAK}

Dampak Anemia gizi besi adalah gangguan performa intelektual dan kognitif, terlambatnya perkembangan psikomotorik, serta penurunan daya tahan terhadap penyakit infeksi. Jenis penelitian Survei Analitik dan desain Cross Sectional. Populasi pada penelitian ini adalah seluruh siswi kelas XI dan XII SMAN 11 Kota Bengkulu berjumlah 140 siswi. Sampel penelitian diambil dengan teknik Accidental Sampling yaitu sebanyak 83 siswi. Data yang digunakan adalah data primer dan sekunder menggunakan kuesioner berupa google form diolah secara univariat dan bivariat dengan uji statistik Chi-Square $\left(\chi^{2}\right)$. Hasil penelitian menunjukkan bahwa dari 83 siswi terdapat 41 siswi $(49,4 \%)$ berpengetahuan baik, 44 siswi $(53,0 \%)$ bersikap favorable, dan 45 siswi $(54,2 \%)$ melakukan upaya pencegahan anemia gizi besi baik. Secara statistik tidak ada hubungan antara pengetahuan dengan upaya pencegahan anemia gizi besi dan tidak ada hubungan antara sikap dengan upaya pencegahan anemia gizi besi. Disarankan kepada pihak sekolah untuk rutin melakukan kegiatan edukasi guna menambah wawasan di bidang kesehatan terutama tentang anemia gizi besi untuk para siswi agar mereka dapat berperan lebih aktif dalam melakukan pencegahan anemia gizi besi.

Kata kunci: anemia gizi besi, pengetahuan, sikap, upaya pencegahan

\section{PENDAHULUAN}

Kesehatan seorang remaja putri sebagai calon seorang ibu dan sekaligus sebagai penerus bangsa perlu menjadi perhatian utama. Hal ini berkaitan juga dengan target Sustainable Development Goals (SDGs) yang masih memerlukan upaya keras untuk pencapaiannya, yaitu kesehatan ibu melahirkan. Dalam siklus hidup, tahap masa remaja terutama remaja putri sangat penting, karena pada masa ini terjadi proses tumbuh kembang, sehingga bila proses ini berlangsung secara optimal akan menghasilkan remaja putri yang sehat dan pada akhirnya akan menghasilkan calon ibu yang sehat pula. United Nations Population Fund (UNFPA) 
menyatakan bahwa ketika remaja perempuan diberi kesempatan untuk mengakses pendidikan dan kesehatan mereka, termasuk kesehatan reproduksi, akan menciptakan peluang bagi remaja untuk merealisasikan potensinya sehingga remaja dapat mengelola dengan baik masa depan diri mereka, keluarga, dan masyarakat (BKKBN, 2016).

Remaja putri merupakan salah satu kelompok yang rentan mengalami anemia. Hal ini dapat dibuktikan dengan data dari World Health Organization (WHO) tahun 2015 yang menunjukkan bahwa prevalensi anemia di dunia adalah berkisar 40,0$88,0 \%$. di Asia Tenggara. Sebanyak 25,0$40,0 \%$ remaja putri mengalami kejadian anemia tingkat ringan dan berat (WHO, 2015).

Di dunia diperkirakan sekitar 50,0\%$80,0 \%$ anemia disebabkan oleh defisiensi besi (Savitry, Arifin, \& Asnawati, 2017). Di beberapa negara prevalensi anemia defisiensi besi pada remaja putri yaitu : $82,5 \%$ di Bangladesh, 23,0\% di China, dan $42,2 \%$ di Filipina dan $74,7 \%$ di India (Demaeyer, 2003 \& Kotecha, 2000 dalam Riyanto \& Lestari (2017).

Anemia merupakan masalah kesehatan utama di masyarakat yang sering dijumpai di seluruh dunia, terutama di negara berkembang seperti Indonesia. Penduduk dunia yang mengalami anemia berjumlah sekitar $30,0 \%$ atau 2,20 miliar orang dengan sebagian besar diantaranya tinggal di daerah tropis. Prevalensi anemia secara global sekitar 51,0\% (Suryani, Hafiani, \& Junita, 2015).

Prevalensi nasional anemia di Indonesia berdasarkan data Riskesdas tahun 2013, yaitu mencapai 21,7\%. Proporsi kejadian anemia di Indonesia menurut karakteristik jenis kelamin perempuan lebih mendominasi jika dibandingkan dengan laki-laki, persentase pada perempuan 23,9\% dan laki-laki 18,4\% (Kemenkes RI, 2013). Persentase kejadian anemia di Indonesia pada usia 15-24 tahun sebesar $32,0 \%$.Prevalensi kejadian anemia pada perempuan sebesar 27,2\% (Kemenkes RI, 2018).

Anemia defisiensi besi dapat mengganggu performa intelektual dan kognitif, serta menimbulkan terlambatnya perkembangan psikomotorik, menurunnya daya tahan terhadap penyakit infeksi, serta dan meningkatnya kerentanan mengalami keracunan. Pada populasi yang mengalami kekurangan zat besi, kematian akibat penyakit infeksi meningkat karena kurangnya zat besi berdampak pada sistem imun. Anemia juga berdampak pada produktivitas kerja dan juga menyebabkan kelelahan (Fikawati, Syafiq, \& Arinda 2017) Kelainan tersebut merupakan penyebab disabilitas kronik yang berdampak besar terhadap kondisi kesehatan, ekonomi, dan kesejahteraan sosial (Suryani, Hafiani, \& Junita, 2015).

Pengetahuan yang baik berpengaruh terhadap status anemia remaja putri. Pengetahuan tersebut bukan dari teori ilmu saja melainkan dari cara memilih bahan makanan agar dapat meningkatkan kadar hemoglobin sehingga status anemianya dalam kategori tidak anemia. Pengetahuan gizi sangat mempengaruhi kecenderungan remaja putri dalam memilih sumber bahan makanan dengan nilai gizi yang tinggi zat besi. Selain itu pengetahuan gizi yang terfokus pada sumber bahan makanan yang menghambat penyerapan zat besi itu sangat penting, agar status anemia pada remaja putri dapat terkendali ke arah normal (Ahmady, Hapzah, \& Mariana, 2016).

Hasil penelitian Setyowati, Riyanti, \& Indraswari (2017) menunjukkan bahwa terdapat hubungan yang signifikan antara pengetahuan dengan perilaku pencegahan anemia di wilayah kerja Puskesmas Ngemplak Simongan. Hasil penelitian Nurbaiti (2019) menunjukkan bahwa terdapat hubungan yang signifikan antara pengetahuan dengan pencegahan anemia di SMAN 4 Kota Jambi

Sikap adalah reaksi atau respon yang masih tertutup terhadap suatu stimulus atau objek yang kemudian diyakini dan akan 
menimbulkan kecenderungan untuk bertindak sesuai dengan yang di yakininya. Sikap belum merupakan tindakan atau praktik yang dapat secara langsung dapat meningkatkan kadar hemoglobin. Sikap merupakan faktor yang mempermudah terbentuknya perilaku upaya pencegahan anemia. Sikap yang mendukung terhadap pencegahan anemia gizi akan mempengaruhi seseorang untuk mencegah dan menanggulangi anemia (Putri \& Muwakidah, 2018).

Hasil penelitian Lestari (2018) menunjukkan bahwa terdapat hubungan antara sikap dengan upaya pencegahan anemia pada remaja putri di Pondok Pesantren wilayah Jenu Kabupaten Tuban. Hasil penelitian Sari \& Anggraini (2020) mengemukakan bahwa sikap tidak berhubungan dengan upaya pencegahan anemia pada mahasiswa Program Studi kebidanan Poltekkes Kemenkes Semarang.

Program pemerintah Indonesia yang fokus terhadap penanggulangan anemia remaja putri yakni Program Pencegahan dan Penanggulangan Anemia Gizi Besi (PPAGB) dengan sasaran anak Sekolah Menengah Pertama (SMP) dan Sekolah Menengah Atas (SMA) melalui pemberian suplementasi kapsul zat besi (Permatasari, Briawan, \& Madanijah, 2018). Berdasarkan informasi dari petugas bagian Gizi di Puskesmas Kandang, program tersebut telah berjalan dengan lancar dengan cara membagikan tablet tambah darah (TTD) ke sekolah-sekolah yang ada di wilayah kerja Puskesmas Kandang yang salah satunya adalah SMAN 11 Kota Bengkulu.

Berdasarkan Survey awal yang di lakukan oleh peneliti pada tanggal 23 Maret 2020 di SMAN 11 Kota Bengkulu, dari 10 siswi yang sudah dicek menggunakan Alat CCHB fingerprint, terdapat hasil 5 siswi mengalami kejadian anemia dan 5 siswi tidak mengalami kejadian anemia. Survey selanjutnya dilakukan pada tanggal 10 Juni 2020 menggunakan sistem online (daring). Berdasarkan kuesioner tentang pengetahuan anemia yang disebarkan oleh peneliti, dari 10 siswi, terdapat 2 siswi berpengetahuan baik, 5 siswi berpengetahuan cukup dan 3 siswi berpengetahuan kurang.

Penelitian tentang upaya pencegahan anemia gizi besi pada remaja putri belum pernah dilakukan sebelumnya di Kota Bengkulu. Tujuan penelitian adalah untuk mempelajari hubungan pengetahuan dan sikap dengan upaya pencegahan anemia gizi besi pada siswi di SMAN 11 Kota Bengkulu.

\section{METODE}

Penelitian ini dilaksanakan di SMAN 11 Kota Bengkulu pada tanggal 02 - 04 Juli 2020. Penelitian ini menggunakan jenis Survey Analitik dengan desain Cross Sectional. Populasi dalam penelitian ini adalah seluruh siswi kelas XI dan XII SMAN 11 Kota Bengkulu tahun ajaran 2020/2021 yaitu sebanyak 83 siswi. Teknik pengambilan sampel dalam penelitian ini adalah Accidental Sampling. Teknik pengumpulan menggunakan data primer dan sekunder. Pengumpulan data primer dilakukan secara online (daring) dikarenakan pandemi Covid-19. Peneliti memberikan link google form untuk pengisian kuesioner kepada wali kelas XI dan XII, lalu wali kelas mengirimkan link google form tersebut kepada grup WhatsApp kelas masing-masing. Jangka waktu pengembalian kuesioner selama 2-3 hari.

Pada pengukuran upaya pencegahan anemia gizi besi, hasil ukur terbagi menjadi 2 yaitu tidak baik jika skor < median dan baik jika skor $\geq$ median. Pada pengukuran pengetahuan hasil terbagi menjadi 3 hasil ukur yaitu kurang (jika hasil persentase jawaban benar < 56,0\%), cukup (jika persentase jawaban benar 56,0\%-75,0\%), dan baik (jika hasil persentase jawaban benar 76,0\%-100,0\%. Pada pengukuran sikap terbagi menjadi 2 hasil ukur yaitu unfavorable jika skor jawaban < median dan favorable jika skor jawaban $\geq$ median. Analisis data dilakukan dengan cara univariat dan bivariat. Analisis bivariat menggunakan uji statistik Chi-Square $\left(\chi^{2}\right)$. 
Untuk mengetahui keeratan hubungan menggunakan Contingency Coefficient (C).

\section{HASIL}

\section{Analisis Univariat}

Analisis univariat bertujuan untuk mengetahui distribusi frekuensi variabel bebas (pengetahuan dan sikap) dan variabel terikat (upaya pencegahan anemia gizi besi). Hasil analisis univariat adalah sebagai berikut :

Tabel 1. Distribusi Frekuensi Pengetahuan Siswi

\begin{tabular}{cccc}
\hline No. & Pengetahuan & Frekuensi & Persentase (\%) \\
\hline 1 & Kurang & 6 & 7,2 \\
2 & Cukup & 36 & 43,4 \\
3 & Baik & 41 & 49,4 \\
\hline & Jumlah & 83 & 100,0
\end{tabular}

Dari Tabel 1 menunjukkan bahwa dari 83 siswi, terdapat 6 siswi $(7,2 \%)$ berpengetahuan kurang, 36 siswi $(43,4 \%)$ berpengetahuan cukup, dan 41 siswi $(49,4 \%)$ berpengetahuan baik di SMAN 11 Kota Bengkulu.
Tabel 2. Distribusi Frekuensi Sikap Siswi

\begin{tabular}{cccc} 
No. & Sikap & Frekuensi & $\begin{array}{c}\text { Persentase } \\
(\mathbf{\%})\end{array}$ \\
\hline 1 & Unfavorable & 39 & 47,0 \\
2 & Favorable & 44 & 53,0 \\
\hline & Jumlah & 83 & 100,0 \\
\hline
\end{tabular}

Dari Tabel 2 menunjukkan bahwa dari 83 siswi, terdapat 39 siswi $(47,0 \%)$ dengan sikap unfavorable dan 44 siswi $(53,0 \%)$ dengan sikap favorable di SMAN 11 Kota Bengkulu di SMAN 11 Kota Bengkulu.

Tabel 3. Distribusi Frekuensi Upaya Pencegahan Anemia Gizi Besi

\begin{tabular}{cccc}
\hline No. & $\begin{array}{c}\text { Upaya } \\
\text { Pencegahan } \\
\text { AGB }\end{array}$ & Frekuensi & $\begin{array}{c}\text { Persentase } \\
(\boldsymbol{\%})\end{array}$ \\
\hline 1 & Baik & 45 & 54,2 \\
2 & Tidak baik & 38 & 45,8 \\
\hline & Jumlah & 83 & 100,0 \\
\hline
\end{tabular}

Dari Tabel 3 menunjukkan bahwa dari 83 siswi, terdapat 45 siswi $(54,2 \%)$ dengan upaya pencegahan anemia gizi besi baik dan 38 siswi $(45,8 \%)$ dengan upaya pencegahan anemia gizi besi tidak baik di SMAN 11 Kota Bengkulu.

Tabel 4. Hubungan Pengetahuan dengan Upaya Pencegahan Anemia Gizi Besi

\begin{tabular}{|c|c|c|c|c|c|c|}
\hline \multirow{4}{*}{ Pengetahuan } & \multirow{2}{*}{\multicolumn{2}{|c|}{$\begin{array}{c}\text { Upaya Pencegahan Anemia } \\
\text { Gizi Besi }\end{array}$}} & \multirow{3}{*}{ Total } & \multirow{4}{*}{$\chi^{2}$} & \multirow{4}{*}{$\mathrm{p}$} & \multirow{4}{*}{$\mathrm{C}$} \\
\hline & & & & & & \\
\hline & \multirow{2}{*}{$\begin{array}{c}\text { Tidak Baik } \\
\text { F }(\%)\end{array}$} & Baik & & & & \\
\hline & & F (\%) & $\mathrm{F}(\%)$ & & & \\
\hline Kurang & $3(50,0)$ & $3(50,0)$ & $6(100,0)$ & & & \\
\hline Cukup & $19(52,8)$ & $17(47,2)$ & $36(100,0)$ & 1507 & 0471 & \\
\hline Baik & $16(39,0)$ & $25(61,0)$ & $41(100,0)$ & 1,507 & $0,4 / 1$ & 0,134 \\
\hline Total & $38(45,8)$ & $45(54,2)$ & $83(100,0)$ & & & \\
\hline
\end{tabular}

Berdasarkan dari Tabel 4 dapat diketahui bahwa dari 6 siswi berpengetahuan kurang, terdapat 3 siswi $(50,0 \%)$ melakukan upaya pencegahan anemia gizi besi tidak baik dan 3 siswi $(50,0 \%)$ melakukan upaya pencegahan anemia gizi besi baik. Dari 36 orang siswi berpengetahuan cukup, terdapat 19 siswi $(52,8 \%)$ melakukan upaya pencegahan anemia gizi besi tidak baik dan 17 siswi $(47,2 \%)$ melakukan upaya pencegahan anemia gizi besi baik. Dari 41 siswi berpengetahuan baik, terdapat 16 siswi $(39,0 \%)$ melakukan upaya pencegahan anemia gizi besi tidak baik dan ada 25 siswi $(61,0 \%)$ melakukan upaya pencegahan anemia gizi besi baik. Hasil uji Chi-Square diperoleh nilai $\chi^{2}=1,507$ dengan $\mathrm{p}=0,471$. Karena nilai $\mathrm{p}>0,05$, maka secara statistik tidak ada hubungan pengetahuan dengan upaya pencegahan anemia gizi besi di SMAN 11 Kota Bengkulu. 
Tabel 5. Hubungan Sikap dengan Upaya Pencegahan Anemia Gizi Besi

\begin{tabular}{|c|c|c|c|c|c|c|}
\hline \multirow{3}{*}{ Sikap } & \multicolumn{2}{|c|}{ Upaya Pencegahan Anemia Gizi Besi } & \multirow{2}{*}{ Total } & \multirow{3}{*}{$\chi^{2}$} & \multirow{3}{*}{$\mathrm{p}$} & \multirow{3}{*}{$\mathrm{C}$} \\
\hline & Tidak Baik & Baik & & & & \\
\hline & $\mathrm{F}(\%)$ & $\mathrm{F}(\%)$ & $\mathrm{F}(\%)$ & & & \\
\hline Unfavorable & $21(53,8)$ & $18(46,2)$ & $39(100,0)$ & \multirow{3}{*}{1,363} & \multirow{3}{*}{0,243} & \multirow{3}{*}{0,151} \\
\hline Favorable & $17(38,6)$ & $27(61,4)$ & $44(100,0)$ & & & \\
\hline Total & $38(45,8)$ & $45(54,2)$ & $83(100,0)$ & & & \\
\hline
\end{tabular}

Berdasarkan dari Tabel 5 dapat diketahui bahwa dari 39 siswi yang bersikap unfavorable, terdapat 21 siswi $(53,8 \%)$ melakukan upaya pencegahan anemia gizi besi yang tidak baik dan 18 siswi $(46,2 \%)$ melakukan upaya pencegahan anemia gizi besi baik. Dari 44 siswi yang bersikap favorable, terdapat 17 siswi $(38,6 \%)$ melakukan upaya pencegahan anemia gizi besi tidak baik dan 27 siswi $(61,4 \%)$ melakukan upaya pencegahan anemia gizi besi baik.

Hasil uji Chi-Square diperoleh nilai $\chi^{2}$ $=1,363$ dengan $\mathrm{p}=0,243$. Karena nilai p>0,05, maka secara statistik tidak ada hubungan sikap dengan upaya pencegahan anemia gizi besi pada siswi di SMAN 11 Kota Bengkulu.

\section{PEMBAHASAN}

\section{Hubungan Pengetahuan dengan Upaya Pencegahan Anemia Gizi Besi}

Berdasarkan hasil analisis bivariat didapatkan bahwa dari $6 \quad$ siswi berpengetahuan kurang, terdapat 3 siswi melakukan upaya pencegahan anemia gizi besi baik. Berdasarkan hasil wawancara dengan responden, responden merupakan seorang atlet Volly Ball sehingga penting bagi responden untuk menjaga kesehatan tubuh khususnya asupan makanan yang kaya akan zat besi dan orang tua responden adalah pedagang buah dan sayuran di pasar tradisional sehingga kebutuhan asupan zat gizi terpenuhi.

Dari 36 siswi berpengetahuan cukup, terdapat 19 siswi melakukan upaya pencegahan anemia gizi besi tidak baik. Berdasarkan hasil wawancara dengan responden, responden merupakan kalangan ekonomi menengah ke bawah sehingga tidak mampu untuk memenuhi kebutuhan gizi, orang tua mempunyai kesibukan sebagai pedagang sehingga tidak sempat untuk memperhatikan anaknya, dan responden terlalu memikirkan body image sehingga sering melakukan diet.

Dari 41 siswi berpengetahuan baik, terdapat 16 siswi melakukan upaya pencegahan anemia gizi besi tidak baik. Berdasarkan hasil wawancara dengan responden, responden tidak dapat mengkonsumsi pil tablet tambah darah (TTD), pemilih makanan, dan tidak suka sayuran.

Hasil uji Chi-Square menunjukan bahwa tidak ada hubungan antara pengetahuan dengan upaya pencegahan anemia gizi besi pada siswi di SMAN 11 Kota Bengkulu. Artinya bahwa pengetahuan tidak menentukan upaya pencegahan anemia gizi besi pada siswi di SMAN 11 Kota Bengkulu.

Hasil penelitian tidak sejalan dengan teori yang dikemukakan oleh Khomsan (2000) yang menyatakan bahwa perilaku, termasuk pola hidup dan kebiasaan makan akan bertahan lebih lama jika dipengaruhi oleh pengetahuan. Pengetahuan adalah hasil dari tahu yang terjadi setelah melakukan penginderaan terhadap suatu obyek tertentu. Tindakan seseorang dibentuk oleh domain pengetahuan atau kognitif (Notoatmodjo, 2003). Pengetahuan mempengaruhi perilaku individu dalam pemeliharaan dan peningkatan kesehatan (Notoatmodjo, 2010).

Hasil penelitian ini tidak sejalan dengan penelitian yang dilakukan oleh Sari \& Anggraini (2020) yang mengemukakan bahwa pengetahuan berhubungan secara 
signifikan dengan upaya pencegahan anemia pada mahasiswa Program Studi Kebidanan Poltekkes Kemenkes Semarang. Setyowati, Riyanti, \& Indraswari (2017) menyatakan bahwa terdapat hubungan yang signifikan antara pengetahuan dengan perilaku pencegahan anemia di wilayah kerja Puskesmas Ngemplak Simongan.

Hasil penelitian Nurbaiti (2019) menunjukkan bahwa ada hubungan yang signifikan antara pengetahuan dengan pencegahan anemia di SMAN 4 Kota Jambi. Adanya hubungan signifikan antara pengetahuan remaja putri tentang anemia dengan perilaku pencegahan anemia pada saat menstruasi di SMK Nusa Bhakti Semarang (Mularsih, 2017).

Hasil penelitian ini berbeda dengan hasil penelitian sebelumnya karena perbedaan usia sampel dan lokasi penelitian. Selain itu, cara ukur untuk mengukur pengetahuan pada penelitian ini berbeda. Karena saat penelitian dilakukan terjadi pandemi Covid 19, maka kuesioner yang diberikan pada penelitian ini menggunakan instrumen google form yang dibagikan secara online (daring) via grup Whatsapp kelas dan durasi pengembalian 2-3 hari sehingga ada kemungkinan responden bisa searching di internet dan bekerja sama dengan responden lain untuk mengisi kuesioner.

\section{Hubungan Sikap dengan Upaya Pencegahan Anemia Gizi Besi}

Berdasarkan hasil analisis bivariat didapatkan bahwa dari 39 siswi bersikap unfavourable, terdapat 18 siswi melakukan upaya pencegahan anemia gizi besi dengan baik. Berdasarkan wawancara dengan responden, responden mempunyai status ekonomi menengah ke atas, aktif dalam kegiatan Pusat Informasi dan Konseling Remaja (PIK-R), memanfaatkan media sosial untuk mempelajari anemia, dan merupakan petugas Unit Kesehatan Sekolah (UKS).

Dari 44 siswi bersikap favorable terdapat 17 siswi melakukan upaya pencegahan anemia gizi besi dengan tidak baik. Berdasarkan hasil wawancara dengan responden, responden tidak cocok mengkonsumsi tablet tambah darah (TTD) dan mempunyai riwayat penyakit maag sehingga tidak bisa mengkonsumsi buah tertentu seperti jeruk yang dapat mendukung penyerapan zat besi.

Hasil uji Chi-Square menunjukan bahwa tidak ada hubungan antara sikap dengan upaya pencegahan anemia pada siswi di SMAN 11 Kota Bengkulu. Artinya bahwa sikap tidak menentukan upaya pencegahan anemia gizi besi pada siswi di SMAN 11 Kota Bengkulu.

Penelitian ini tidak sejalan dengan penelitian yang dilakukan oleh Lestari (2018) bahwa terdapat hubungan yang signifikan antara sikap dengan upaya pencegahan anemia saat menstruasi pada remaja putri di Pondok Pesantren wilayah Jenu Kabupaten Tuban. Hasil penelitian ini berbeda dengan hasil penelitian Lestari (2018) karena perbedaan usia responden dan lokasi penelitian. Selain itu, cara ukur untuk mengukur pengetahuan pada penelitian ini berbeda. Karena saat penelitian dilakukan terjadi pandemi Covid 19, maka kuesioner yang diberikan pada penelitian ini menggunakan instrumen google form yang dibagikan secara online (daring) via grup Whatsapp kelas dan durasi pengembalian 2-3 hari sehingga ada kemungkinan responden bisa searching di internet dan bekerja sama dengan responden lain untuk mengisi kuesioner.

Hasil penelitian sejalan dengan penelitian Sari \& Anggraini (2020) yang mengemukakan bahwa sikap mahasiswa bidan tidak berhubungan dengan upaya pencegahan anemia pada mahasiswa Program Studi Kebidanan Poltekkes Kemenkes Semarang. Penelitian Sulistyorini \& Maysaroh (2019), mengemukakan bahwa tidak ada hubungan antara sikap remaja putri tentang anemia dengan perilaku mengkonsumsi tablet zat besi di RW 12 Genengan Mojosongo Jebres Surakarta.

Menurut Farida (2007), perubahan perilaku remaja putri tidak selalu 
disebabkan oleh pengetahuan. Pengetahuan remaja yang baik belum tentu mengakibatkan praktik pencegahan anemia menjadi baik. Upaya pencegahan anemia dapat dilakukan dengan cara memperkaya asupan zat besi, mengonsumsi tablet tambah darah sebelum dan selama menstruasi, dan pemberian informasi tentang cara pencegahan anemia oleh petugas kesehatan (Tarwoto, 2010).

\section{KESIMPULAN}

Berdasarkan hasil penelitian di atas, maka dapat disimpulkan secara statistik tidak ada hubungan antara pengetahuan dan sikap dengan upaya pencegahan anemia gizi besi pada siswi di SMAN 11 Kota Bengkulu. Disarankan kepada pihak sekolah untuk rutin melakukan kegiatan edukasi tentang Anemia Gizi Besi untuk siswi SMAN 11 Kota Bengkulu agar siswi dapat berperan lebih aktif dalam melakukan pencegahan Anemia Gizi Besi sehingga kejadian Anemia Gizi Besi dapat dicegah.

\section{UCAPAN TERIMA KASIH}

Penulis mengucapkan terima kasih kepada STIKES Tri Mandiri Sakti Bengkulu dan SMAN 11 Kota Bengkulu yang telah memberikan izin dan dukungan untuk pelaksanaan penelitian ini.

\section{DAFTAR PUSTAKA}

Ahmady, Hapzah, \& Mariana, D. (2016). Penyuluhan Gizi dan Pemberian Tablet Besi terhadap Pengetahuan dan Kadar Hemoglobin Siswi Sekolah Menengah Atas Negeri di Mamuju . Jurnal Kesehatan Manarang, 02(01): 15-20. Diunduh dari:

http://journal.poltekkesmamuju.ac.id /index.php/j km

BKKBN. (2016). Data Survei Kesehatan Republik Indonesia. Jakarta: BKKBN.
Farida, I. (2007). Determinan Kejadian Anemia pada Remaja Putri di Kecamatan Gebog Kabupaten Kudus. Thesis. Universitas Diponegoro.

Fikawati, S., Syafiq, A. \& Arinda, V. (2017). Gizi Anak dan Remaja. Depok : Raja Grafindo Persada.

Kemenkes RI. (2018). Laporan Nasional RISKESDAS 2018. Jakarta : Kemenkes RI.

Kemenkes RI. (2013). Riset Kesehatan Dasar. Jakarta: Kemenkes RI.

Khomsan A. (2000). Teknik Pengukuran Pengetahuan Gizi. Bogor : Institut Pertanian Bogor.

Lestari, D. I. N. (2018). Analisis Faktor yang Berhubungan dengan Upaya Pencegahan Anemia Saat Menstruasi pada Remaja Putri di Pondok Pesantren Wilayah Jenu Kabupaten Tuban Penelitian Cross Sectional. Skripsi. Universitas Airlangga.

Mularsih, S. (2017). Hubungan Pengetahuan Remaja Putri tentang Anemia dengan Perilaku Pencegahan Anemia pada Saat Menstruasi di SMK Nusa Bhakti Kota Semarang. Jurnal Kebidanan, 6 (2) : 80-85. Diunduh dari : https://jurnal.unimus.ac.id/index.php /jur_bid/article/view/2652/0.

Notoatmodjo, S. (2010). Promosi Kesehatan dan Ilmu Perilaku. Jakarta : Rineka Cipta.

Notoatmodjo, S. (2003). Pendidikan dan Perilaku Kesehatan. Jakarta : Rineka Cipta.

Nurbaiti (2019). Faktor-Faktor yang Berhubungan dengan Pencegahan Anemia pada Remaja Putri di SMA Negeri 4 Kota Jambi Tahun 2018. Jurnal Ilmiah Universitas Batanghari Jambi, 19 (1) : 84-88. Diunduh dari : http://ji.unbari.ac.id/index.php/ilmia h/article/view/552.

Putri, M. A., \& Muwakidah. (2018) Hubungan Sikap Pencegahan 
Anemia dan Perilaku Mengkonsumsi Tablet Tambah Darah Dengan Kadar Hemoglobin (Hb) Pada Remaja Putri di SMKN 1 Sukoharjo. Skripsi. Universitas Muhammadiyah Surakarta. Diunduh dari: http://eprints.ums.ac.id/id/eprint/626 4.

Permatasari, T., Briawan, D., \& Madanijah, S. (2018). Efektivitas Program Suplementasi Zat Besi pada Remaja Putri di Kota Bogor. Jurnal MKMI, 14(1) : 1-8. Diunduh dari: https://media.neliti.com/media/publi cations/238439-efektifitas-programsuplementasi-zat-bes-277c24be.pdf

Riyanto, R., \& Lestari, G. I. (2017). Kejadian Anemia Berdasarkan Status Gizi, Pengetahuan dan Pola Minum Teh pada Remaja Putri di Pondok Pesantren. Jurnal Kesehatan Metro Sai Wawai, 10 (02), 83-89. Diunduh dari https://ejurnal.poltekkestjk.ac.id/index.php/JKM/article/view /1342.

Sari, M. H. N, \& Anggraini, D. D. (2020). Analisis Sikap dan Pengetahuan terhadap Upaya Pencegahan Anemia pada Mahasiswa Bidan. Jurnal Kebidanan dan Kesehatan Tradisional, 5 (2), 67-149. Diunduh dari

https://jurnalbidankestrad.com/index .php/jkk/article/view/157.

Savitry, N. S. D., Arifin, S., \& Asnawati. (2017). Hubungan Dukungan Keluarga dengan Niat Konsumsi Tablet Tambah Darah pada Remaja Putri. Jurnal Kesehatan dan Kedokteran, 13, 113-18. Diunduh dari

https://ppjp.ulm.ac.id/journal/index. php/jbk/article/view/3447/2992

Setyowati, N. D., Riyanti, E., \& Indraswari, R. (2017). Faktor-Faktor yang Berhubungan dengan Perilaku Makan Remaja Putri dalam Pencegahan Anemia di Wilayah Kerja Puskesmas Ngemplak
Simongan. Jurnal Kesehatan Masyarakat, 5(5) : 1042-1052. Diunduh dari: https://ejournal3.undip.ac.id/index.p hp/jkm/article/view/19233/18259.

Sulistyorini, E., \& Maysaroh, S. (2019). Hubungan Pengetahuan dan Sikap Remaja Putri tentang Anemia dengan Perilaku Mengkonsumsi Tablet Zat Besi di RW 12 Genengan Mojosongo Jebres Surakarta. Jurnal Kebidanan Indonesia, 10(2) : 110121. Diunduh dari : https://jurnal.stikesmus.ac.id/index.p $\mathrm{hp} / \mathrm{JKebIn/article/view/286.}$

Suryani, D., Hafiani, R., \& Junita, R. (2015). Analisis Pola Makan dan Anemia Gizi Besi pada Remaja Putri Kota Bengkulu. Jurnal Kesehatan Masyarakat Andalas 10 (1) : 11-18. Diunduh dari: http://jurnal.fkm.unand.ac.id/index.p $\mathrm{hp} / \mathrm{jkma} /$ article/view/157/167.

Tarwoto. (2010). Kesehatan Remaja Problem dan Solusinya. Jakarta : Salemba Medika.

WHO. (2015). The Global Prevalence Of Anemia in 2011. Geneva: WHO. Diunduh dari

Https://apps.who.int/iris/bitstream/han dle/10665/177094/9789241564960_e ng.pdf;jsessionid=4E542817224E3BE 85788C7AB5B5C50B2? Sequence $=1$. 